\title{
Omnivory by Planktivores Stabilizes Plankton Dynamics, but May Either Promote or Reduce Algal Biomass
}

\author{
José Luiz Attayde, ${ }^{1 *}$ Egbert H. van Nes, ${ }^{2}$ Aderaldo I. L. Araujo, ${ }^{3,4}$ \\ Gilberto Corso, ${ }^{1}$ and Marten Scheffer ${ }^{2}$
}

\begin{abstract}
${ }^{1}$ Centro de Biociências, Universidade Federal do Rio Grande do Norte, Natal, RN, Brazil; ${ }^{2}$ Department of Aquatic Ecology and Water Quality Management, Wageningen University, Wageningen, The Netherlands; ${ }^{3}$ Departamento de Física Teórica e Experimental, UFRN, Natal, RN, Brazil; ${ }^{4}$ Instituto Federal de Ensino, Ciência e Tecnologia do Ceará, Fortaleza, CE, Brazil
\end{abstract}

\begin{abstract}
Classical models of phytoplankton-zooplankton interaction show that with nutrient enrichment such systems may abruptly shift from limit cycles to stable phytoplankton domination due to zooplankton predation by planktivorous fish. Such models assume that planktivorous fish eat only zooplankton, but there are various species of filter-feeding fish that may also feed on phytoplankton. Here, we extend these classical models to systematically explore the effects of omnivory by planktivorous fish. Our analysis indicates that if fish forage on phytoplankton in addition to zooplankton, the alternative attractors predicted by the classical models disappear for all realistic parameter settings, even if omnivorous fish have a strong preference for zooplankton. Our model also shows that the level of fish biomass above which zooplankton collapse should be higher when fish are omnivorous than when fish are zoo-
\end{abstract}

\section{INTRODUCTION}

The theoretical possibility of catastrophic regime shifts in ecosystems has long been recognized

Received 15 July 2009; accepted 1 February 2010; published online 10 April 2010

Authors contribution: JLA conceived the study, ran the simulations and wrote the paper. EHVN ran additional simulations, made the final figures and improved the text. AA and GC contributed with initial simulations and discussions. MS contributed with discussions and also improved the text.

*Corresponding author; e-mail: ATTAYDE@CB.UFRN.BR planktivorous. We also used the model to explore the potential effects of the now increasingly common practice of stocking lakes with filter-feeding fish to control cyanobacteria. Because omnivorous filterfeeding fish forage on phytoplankton as well as on the main grazers of phytoplankton, the net effect of such fish on the phytoplankton biomass is not obvious. Our model suggests that there may be a unimodal relationship between the biomass of omnivorous filter-feeding fish and the biomass of phytoplankton. This implies that to manage for reductions in phytoplankton biomass, heavy stocking or strong reduction of such fish is best.

Key words: alternative stable states; eutrophication; filter-feeding fish; intraguild predation; omnivory; Oreochromis; plankton; tilapia; trophic cascade; trophic dynamics.
(Holling 1973; Noy-Meir 1975; May 1977). However, empirical studies have only recently provided strong evidence for the existence of alternative stability domains in various ecosystems (Scheffer and others 2001; Folke and others 2004). One of the best-studied and most dramatic regime shifts in ecosystems is the loss of water transparency and rooted aquatic plants observed in shallow lakes subjected to human-induced eutrophication (Scheffer and others 1993, 2001). Observations in shallow lakes suggest that over a range of nutrient 
concentrations, such lakes can have two alternative stable states (that is, dynamic regimes): a clear state dominated by aquatic plants and a turbid state characterized by high phytoplankton biomass. This has important implications for the potential of restoring eutrophic shallow lakes, as nutrient reduction alone may have little impact on water clarity due to the resilience of the turbid state.

Fish play a central role in maintaining the turbid state of shallow lakes because, in the absence of aquatic plants, they can control the abundance of key zooplankton grazers such as Daphnia, thus increasing phytoplankton biomass (Jeppesen and others 1997; Scheffer 1998). Moreover, they can resuspend sediments in search for benthic food, increasing turbidity (Zambrano and others 2001), and also translocate nutrients from benthic to pelagic habitats, enhancing phytoplankton growth (Vanni 2002). Therefore, an ecosystem disturbance like a strong reduction of planktivorous/benthivorous fish biomass is often needed to bring the lake back to a stable clear state, only after reduction of external nutrient loading (Jeppesen and others 1997; Perrow and others 1997; Hansson and others 1998).

Previous theoretical analyses on the effects of planktivorous fish on lake plankton dynamics suggest that in most situations, the plankton should show hysteresis in response to predation pressure by fish (Scheffer 1991, 1998; Scheffer and others 2000). Thus, in simple models of zooplanktivory there can be two distinct dynamic regimes, one in which Daphnia is controlled (overexploited) by fish and phytoplankton biomass is high, and another in which Daphnia is relatively unaffected (underexploited) by planktivores and phytoplankton are controlled by Daphnia. Switches from one regime to the other occur abruptly at a critical fish biomass, which in turn depends on the ambient nutrient concentration and climate conditions (Scheffer and others 2000; Scheffer and others 2001).

Although these model predictions are in line with some field observations and experimental results, they are based on the assumption that planktivorous fish affect plankton communities only through size-selective predation on zooplankton (Brooks and Dodson 1965). However, planktivorous fish can have two distinct types of feeding mode: visual particulate feeding on zooplankton and filter feeding on both zooplankton and phytoplankton (Lazzaro 1987). Previous studies suggest that these two contrasting planktivore types might have different effects on the structure of plankton communities (Lazzaro and others 1992; Stein and others 1995; Drenner and others 1996;
Attayde and Menezes 2008). Although the response of plankton communities to visual feeding by fish (that is, size-selective predation on zooplankton) has been the focus of much limnological research, the effects of omnivorous filter-feeding fish have been much less investigated, despite the fact that many (sub) tropical lakes and reservoirs are dominated by filter-feeding species of tilapias and carps (Lazzaro 1997; Jeppesen and others 2007).

Predicting the outcome of an ecosystem disturbance like removing "zooplanktivorous" fish or stocking "phytoplanktivorous" fish to reduce phytoplankton biomass is not trivial, because most planktivorous fish are omnivorous to some extent. Fish omnivory in a three-level food chain simultaneously encompasses three different types of three-species interactions: a linear food chain, two competitors sharing a resource, and two prey sharing a predator (Diehl 1993). The outcome of such complex interactions will depend on the relative strength of each direct and indirect effect of the omnivorous predator (Diehl 1993). Therefore, the expectation that reducing the stock of "zooplanktivorous" fish or stocking "phytoplanktivorous" fish will result in lower phytoplankton biomass should not be taken for granted when planktivorous fish are dominated by omnivorous filter-feeding species (Stein and others 1995; Starling and others 1998; Lazzaro and others 2003; Zhang and others 2008; Okun and others 2008; Figueredo and Giani 2005; Rondel and others 2008).

Omnivorous filter-feeding fish are generally not limited by zooplankton dynamics, as they can also feed on phytoplankton and suspended detritus, thus reaching higher carrying capacity than strict zooplanktivores. This strategy may lead to higher predation pressure on zooplankton (Stein and others 1995; Lazzaro 1997; Jeppesen and others 2005; van Leeuwen and others 2007), thus reducing the chance for large zooplankton to become abundant and weak top-down control of zooplankton on phytoplankton. However, another possible outcome is that consumption of phytoplankton by filter-feeding fish may weaken fish predation pressure on zooplankton and decrease the strength of cascading trophic interactions. Therefore, there is little theoretical or empirical support for the assumption that high levels of fish omnivory in the tropics accounts for the lower abundance of large-bodied zooplankton and therefore lower zooplankton grazing pressure on phytoplankton (Lazzaro 1997; Jeppesen and others 2007; van Leeuwen and others 2007). 
In this paper, we investigate the theoretical implications of omnivory by filter-feeding fish for the plankton dynamics of shallow lakes. We modify a minimal model of planktivory which is known to exhibit catastrophic regime shifts and parameterize the model for a food chain consisting of phytoplankton, Daphnia, and an omnivorous fish, the Nile tilapia (Oreochromis niloticus). Nile tilapia is the most widespread freshwater fish species after the common carp (Cyprinus carpio) and has been introduced in many tropical lakes and reservoirs to increase fish production (Canonico and others 2005; Zambrano and others 2006). Because previous models have shown that the presence of alternative stable states in plankton communities is strongly dependent on primary productivity and fish predation pressure, we focus our analysis on the influences of fish biomass and primary productivity for two contrasting types of planktivores: a zooplanktivorous and an omnivorous filter-feeding fish.

\section{Methods}

\section{Model Description}

Our model is an extension of the minimal model of planktivory developed by Scheffer (1998), and includes a prey switching term to describe omnivory by a filter-feeding fish. Parameter values and units for this model and the following expansions on it are listed in Table 1 together with the relevant sources of information. The model consists of two differential equations, one for phytoplankton (hereby called algae) and another for zooplankton:

$$
\begin{aligned}
\frac{\mathrm{d} A}{\mathrm{~d} t} & =r A\left(1-\frac{A}{K}\right)-g Z \frac{A}{h+A}-\theta_{\mathrm{A}} g_{\mathrm{A}} F \frac{A}{h_{\mathrm{A}}+A}+i(K-A) \\
\frac{\mathrm{d} Z}{\mathrm{~d} t} & =e g Z \frac{A}{h+A}-m Z-\theta_{\mathrm{Z}} g_{\mathrm{Z}} F \frac{Z}{h_{\mathrm{Z}}+Z}
\end{aligned}
$$

The basic growth of algae is logistic, with a maximum growth rate $(r)$, and a carrying capacity $(K)$. The algal equation has two consumption terms to account for the consumption by zooplankton and fish. The first consumption term depends on the zooplankton biomass $(Z)$ and its weight specific maximum consumption rate $(g)$ and on algal biomass $(A)$. The second consumption term depends on the fish biomass $(F)$, its weight specific maximum consumption rate of algae $\left(g_{\mathrm{A}}\right)$ and its preference for algae $\left(\theta_{\mathrm{A}}\right)$ as well as on algal biomass. The dependence of zooplankton and fish consumptions on phytoplankton biomass is formulated as Monod functions representing simple saturating
(Holling type II) functional responses with fixed half-saturation values ( $h$ and $h_{\mathrm{A}}$ ). An extra term is added into the algal equation to account for the stabilizing effect of spatial heterogeneity in grazing pressure (Scheffer and De Boer 1995). The ingested algae are converted into zooplankton growth with certain efficiency $(e)$ and zooplankton suffers losses due to respiration and natural mortality at a fixed rate $(m)$. To account for the effect of predation by fish on zooplankton, we add another loss term to the zooplankton equation, which depends on fish biomass $(F)$, its weight specific maximum consumption rate of zooplankton $\left(g_{\mathrm{z}}\right)$, its preference for zooplankton $\left(\theta_{\mathrm{Z}}\right)$, the half-saturation concentration of zooplankton for fish functional response $\left(h_{\mathrm{Z}}\right)$ as well as on zooplankton biomass $(Z)$.

Omnivorous filter-feeding fish are known to exhibit two different feeding modes (that is, visual particulate feeding and filter feeding), being able to switch from one feeding mode to another depending on their size and on the size and relative abundance of algae and zooplankton (Lazzaro 1987). To account for this we include a prey switching function into the model according to Post and others (2000) as follows:

$$
\begin{aligned}
& \theta_{\mathrm{Z}}=\frac{p Z}{p Z+(1-p) A} \\
& \theta_{\mathrm{A}}=1-\theta_{\mathrm{Z}}=\frac{(1-p) A}{p Z+(1-p) A}
\end{aligned}
$$

where $p$ is the food preference $(0 \leq p \leq 1)$ of fish for zooplankton. At $p=1$, fish prey only on zooplankton $(Z)$ and at $p=0$, fish feed only on algae $(A)$. At $p=0.5$, fish eat both $Z$ and $A$ in proportion to their biomass (that is, without prey preference). This formulation of prey preference maintains the underlying type-II functional response of the predator at $p=0$ and $p=1$, but allows prey switching at $0<p<1$ (Post and others 2000). Prey switching occurs so that, as the abundance of one food type declines, more of the predator's diet is derived from the other food type. This can produce a sigmoidal (type-III-like) functional response, which is known to stabilize model systems.

Note that in this model, fish biomass is considered a constant that can be manipulated rather than a variable that responds to plankton dynamics. This seems a reasonable assumption because plankton dynamics are much faster than fish dynamics. However, planktivorous fish populations are not really constant in nature and we would better interpret our minimal model of planktivory as a reasonable representation of field mesocosms where experiments are carried out to investigate 
Table 1. Overview of Symbols Used in the Equations and their Dimensions, Default Values and Meaning

\begin{tabular}{|c|c|c|c|c|}
\hline Symbol & Units & Value & Definition & Reference \\
\hline$A$ & $\operatorname{mg~DW~} \mathrm{l}^{-1}$ & - & Concentration of phytoplankton & \\
\hline e & $\mathrm{g} \mathrm{g}^{-1}$ & 0.6 & $\begin{array}{l}\text { Efficiency of conversion of algae into growth } \\
\text { of zooplankton }\end{array}$ & Scheffer 1998 \\
\hline$F$ & $\operatorname{mg~DW~} \mathrm{l}^{-1}$ & - & Concentration of fish & \\
\hline$g$ & $\mathrm{~g} \mathrm{~g}^{-1} \mathrm{day}^{-1}$ & 0.4 & Maximum grazing rate of zooplankton & Scheffer 1998 \\
\hline$g_{\mathrm{A}}$ & $\mathrm{g} \mathrm{g}^{-1}$ day $^{-1}$ & 0.2 & Maximum grazing rate of fish & Turker and others 2003 \\
\hline$g_{\mathrm{Z}}$ & $\mathrm{g} \mathrm{g}^{-1}$ day $^{-1}$ & 0.1 & Maximum predation rate of fish & \\
\hline$h$ & $\mathrm{mg} \mathrm{DW} \mathrm{l}^{-1}$ & 0.6 & $\begin{array}{l}\text { Half-saturation concentration of algae } \\
\text { for } \mathrm{Z} \text { functional response }\end{array}$ & Scheffer 1998 \\
\hline$h_{\mathrm{A}}$ & mg DW $\mathrm{l}^{-1}$ & 10 & $\begin{array}{l}\text { Half-saturation concentration of algae } \\
\text { for fish functional response }\end{array}$ & Turker and others 2003 \\
\hline$h_{\mathrm{Z}}$ & $\mathrm{mg} \mathrm{DW} \mathrm{l}^{-1}$ & 10 & $\begin{array}{l}\text { Half-saturation concentration of } \mathrm{Z} \\
\text { for fish functional response }\end{array}$ & \\
\hline$i$ & $\mathrm{~g} \mathrm{~g}^{-1}$ day $^{-1}$ & 0.02 & Inflow of phytoplankton from ungrazed parts & Scheffer 1998 \\
\hline$K$ & $\mathrm{mg} \mathrm{DW} \mathrm{l}^{-1}$ & 15 & Carrying capacity for phytoplankton & \\
\hline$m$ & day $^{-1}$ & 0.15 & Mortality rate of zooplankton & Scheffer 1998 \\
\hline$p$ & & - & Prey preference of fish & \\
\hline$r$ & day $^{-1}$ & 0.5 & Maximum growth rate of $\mathrm{A}$ & Scheffer 1998 \\
\hline$Z$ & $\mathrm{mg} \mathrm{DW} \mathrm{l}^{-1}$ & - & Concentration of zooplankton & \\
\hline
\end{tabular}

effects of planktivorous fish on plankton treating fish biomass as a constant.

\section{Model Analysis}

We start our analysis by plotting the zero-growth isoclines of the two plankton organisms (that is, algae and Daphnia) for different values of fish biomass and two contrasting planktivore types: zooplanktivorous $(p=1)$ and omnivorous filterfeeding fish without prey preference $(p=0.5)$. We use the isocline approach to understand which types of equilibria can arise under different levels of fish biomass and feeding modes. We also conducted simulations that show the nature of the asymptotic behavior (attractors) of the model under some conditions. Because bifurcations are of particular interest, as they mark crucial changes in the model behavior, we perform a bifurcation analysis by looking at the combined effects of fish biomass $(F)$ and the carrying capacity for phytoplankton $(K)$. The analyses were performed with the software GRIND for MATLAB which is available for free download at www.aew.wur.nl/UK/GRIND.

\section{RESUlts}

We first consider the effect of different fish densities on isoclines of zero-growth for zooplankton and phytoplankton. Without fish the model equals the classical Rosenzweig-MacArthur model with a vertical zooplankton isocline $(\mathrm{d} Z / \mathrm{d} t=0)$. If fish are able to feed only on zooplankton $(p=1)$ then the algal isocline $(\mathrm{d} A / \mathrm{d} t=0)$ remains unaffected while the zooplankton isocline $(\mathrm{d} Z / \mathrm{d} t=0)$ starts bending out as fish biomass increases, (Figure $1 \mathrm{~A}-\mathrm{D})$ and two non-trivial equilibrium points $(Z \neq 0)$ can arise (Figure 1B): a saddle point (gray circle) and an unstable equilibrium marking the center of a limit cycle (white circle). If the amount of fish increases further, the limit cycle touches the saddle point and the limit cycle is no longer an attractor (Figure 1C). At very high fish densities (Figure 1D), zooplankton cannot survive and there is only one stable equilibrium. However, if fish are able to feed on both phyto- and zooplankton $(p=0.5)$, both isoclines are affected by an increase in fish biomass and only one non-trivial equilibrium point can occur (Figure $1 \mathrm{E}-\mathrm{H}$ ). This unique equilibrium can be either the unstable center of a limit cycle (Figure 1E, F, open circle) or a stable node (Figure lG, H, black circle) depending on the fish biomass. At unrealistically high levels of omnivorous fish, zooplankton can go extinct while algae are kept far below their carrying capacity due to fish grazing (Figure $1 \mathrm{H}$ ).

An overview of the effect of fish on the behavior of our model is obtained if we plot the attractors in the plankton as a function of fish biomass (Figure 2). Many scenarios may arise when fish are able to feed only on zooplankton (Scheffer and others 2000) but the essence can be captured by the 

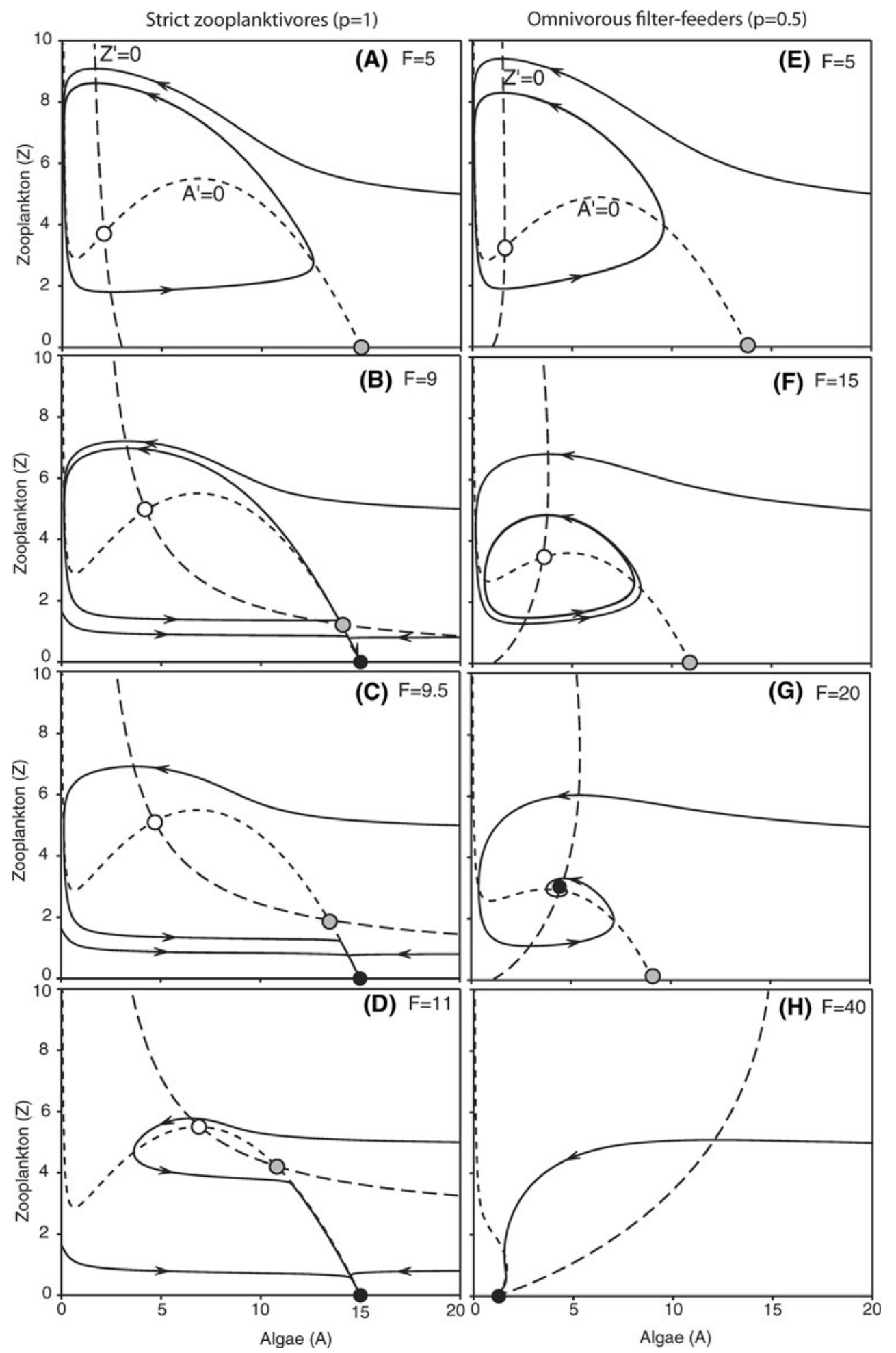

Figure 1. Effects of increasing planktivorous fish biomass $(F)$ on the zero-growth isoclines of the plankton model when fish are strict

zooplanktivores (left) and omnivorous filter-feeders with no prey preference (right). One or few arbitrary trajectories are plotted (solid lines with arrows). Black circles denote stable equilibria, white circles denote unstable equilibria and gray circles denote saddle points. For parameter values we refer to Table 1, the amount of fish $(F)$ is shown in the figures. following case assuming that plankton interaction has a cyclic attractor (Scheffer and Rinaldi 2000). If we start from zero fish and gradually increase the biomass of zooplanktivorous fish $(p=1)$, the plankton system shows limit cycles until point $O$ is reached (Figure 2A, B). At this point, the ampli- tude of plankton oscillations is large enough to hit the border of the attraction basin of the limit cycle and the system collapses into a state in which zooplankton go extinct and phytoplankton are at carrying capacity (Figure 2A, B). The technical term for this type of transition is "homoclinic 

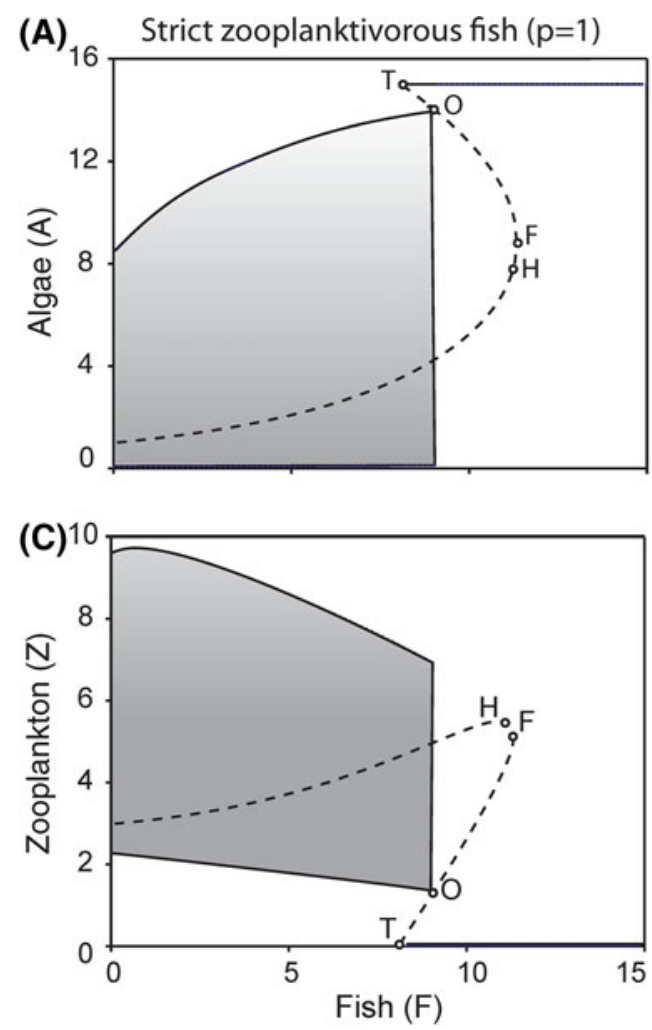

(B)

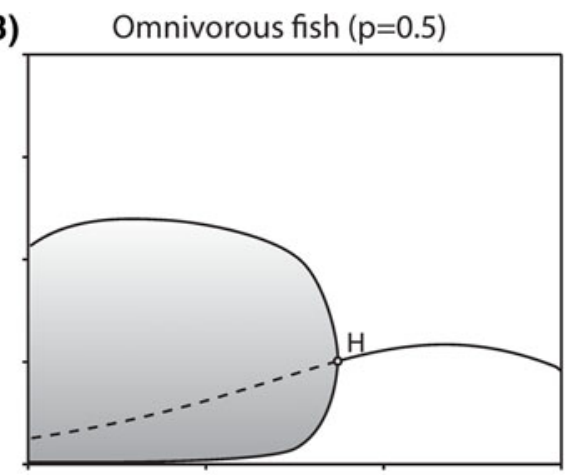

(D)

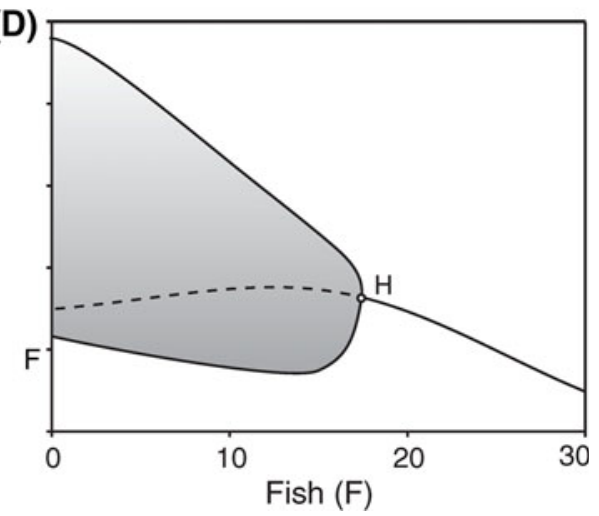

Figure 2. Response to fish biomass of the equilibrium concentration of algae $(A)$ and zooplankton $(Z)$ for strict zooplanktivorous (left) and an omnivorous filter-feeding fish with no prey preference (right). In the shaded area the equilibrium is unstable and we plot the amplitude of the limit cycles, dashed lines are unstable equilibria.

Special points: $T$ transcritical bifurcation, $O$ homoclinic bifurcation, $H$ Hopf bifurcation and $F$ fold bifurcation. bifurcation". The essence of this bifurcation in biological terms is that zooplankton collapse because of food-shortage (the limit cycle), and that this brings the population down sufficiently low enough to let a relatively small amount of fish prevent recovery (the overexploited state). If we subsequently decrease fish biomass, the system stays in the "green equilibrium" until point $T$ (that is, the "Transcritical bifurcation") is reached, zooplankton can invade the system and the limit cycle of plankton returns. Between points $O$ and $T$, the cyclic attractor and the "green equilibrium" are alternative states. The system will settle to either one of these states, depending on the initial state of a simulation run. The line of unstable equilibrium points (saddle points) between the points $O$ and $T$ marks the border of the attraction basins of the two alternative states.

Conversely, if fish are omnivorous $(p=0.5)$, there is no homoclinic bifurcation and the zooplankton coexist over a broad range of fish biomass (Figure 2C, D). With increasing fish densities the cycles become gradually smaller and disappear finally at point $H$ (that is, the "Hopf bifurcation"). Note that this system can sustain about twice as much biomass of fish without any collapse of zooplankton than the system with zooplanktivorous fish (Figure 2). This implies that omnivory by planktivorous fish stabilizes zooplankton oscillations and helps to prevent the homoclinic bifurcation that triggers the catastrophic collapse of zooplankton and the consequent regime shift in plankton. Note also that the biomass of algae now has a maximum with increasing fish biomass (Figure $2 \mathrm{C}$ ), the result of increasing fish biomass is thus hard to predict.

The above results show that the behavior of the model strongly depends on the fish biomass $(F)$ and the prey preference term $(p)$. To investigate the effects of planktivorous fish on the model behavior along a gradient of nutrient enrichment we performed a two-dimensional bifurcation analysis by looking at the combined effects of fish biomass $(F)$ and the carrying capacity for phytoplankton $(K)$ (Figure 3). A remarkable difference between the two planktivore types is that alternative attractors can arise over a range of $K$ and $F$ values only when fish are strictly zooplanktivorous (Figure 3A). Therefore, omnivory by fish prevents the alternative states (that is, dynamic regimes) that occur in the model when fish feed only on zooplankton. Even a small degree of omnivory $(p=0.9)$ is sufficient to prevent catastrophic regime shifts in plankton dynamics over realistic ranges of fish biomass and algal carrying capacity (Figure 3B). Another important difference is that the bifurcation 


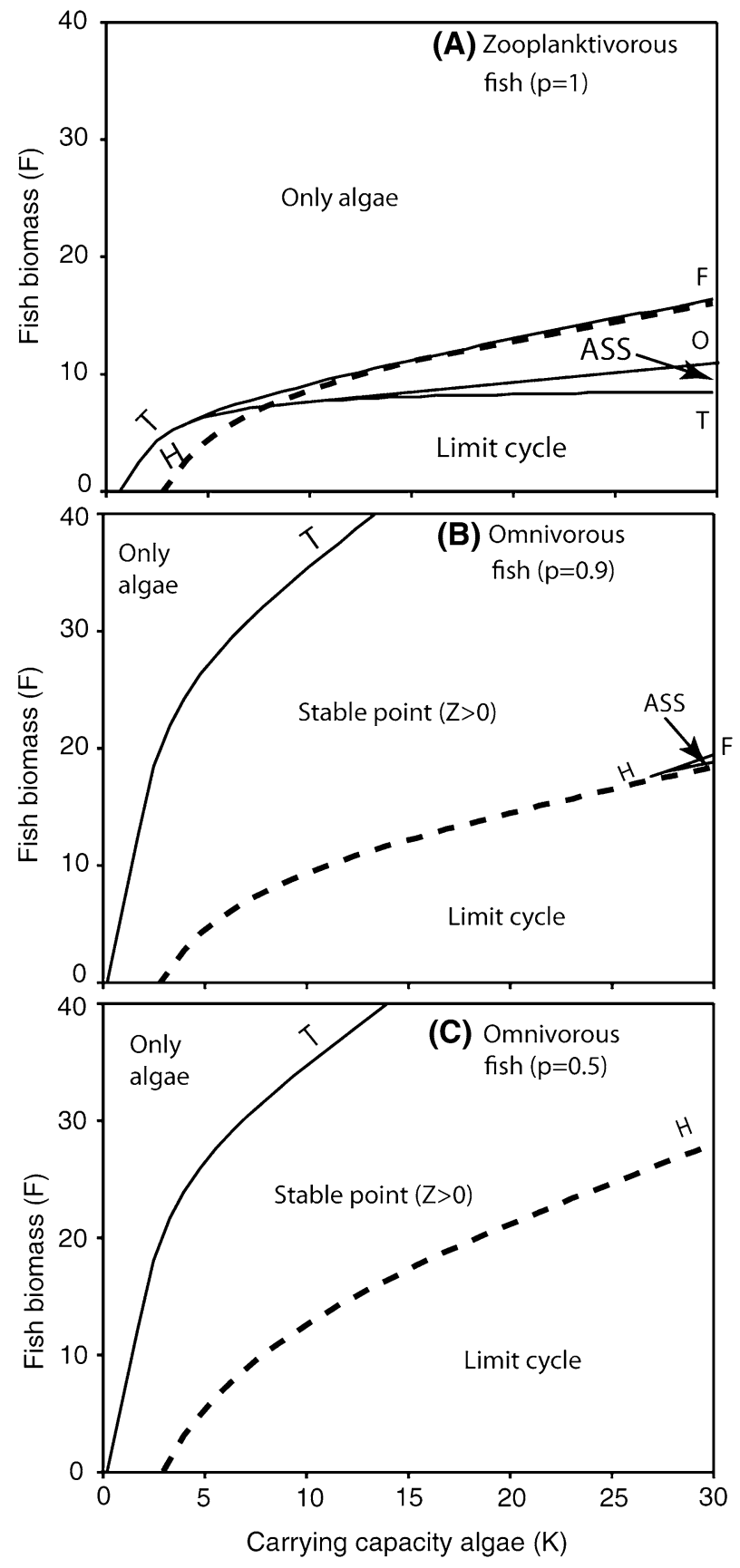

Figure 3. Two dimensional bifurcation plots with the biomass of fish $(F)$ and the carrying capacity $(K)$ as bifurcation parameters for three fish types: A strict zooplanktivorous fish $(p=1), \mathbf{B}$ omnivorous fish with a strong preference for zooplankton $(p=0.9)$, and C omnivorous filter-feeding fish with no prey preference $(p=0.5)$. $T$ transcritical bifurcation, $O$ homoclinic bifurcation, $H$ Hopf bifurcation, and $F$ fold bifurcation. ASS is an area with alternative stable states.

line above which zooplankton go extinct occurs at a much higher level of fish biomass when fish are omnivorous than when fish are zooplanktivorous (Figure 3).

\section{Discussion}

Our model supports the idea that omnivory decreases the amplitude of limit cycles and increases the persistence of intermediate consumers (that is, zooplankton). Omnivory by planktivorous fish, even if they have a strong preference for zooplankton, can prevent catastrophic shifts in the dynamics of plankton. The model also suggests that omnivory increases the amount of fish that the system can support without causing the collapse of zooplankton. This clearly contradicts the general idea that a higher abundance of omnivorous fish in (sub) tropical lakes would lead to virtual extinction of large-bodied zooplankton. Finally, we find a unimodal relationship between the equilibrium biomass of phytoplankton and the biomass of omnivorous filter-feeding fish. This relationship may have important consequences for the biomanipulation of eutrophic and hypereutrophic lakes using filter-feeding fish.

Omnivory is generally defined as feeding on more than one trophic level and has been the subject of numerous theoretical and empirical studies in recent years. However, most of these studies examine the conditions necessary for coexistence between an omnivore and an intermediate consumer at equilibrium (for example, Polis and others 1989; Holt and Polis 1997; Mylius and others 2001; Diehl and Feissel 2000; Diehl 2003). Under non-equilibrium conditions, previous theoretical work has shown that the presence of omnivory can locally stabilize and enhance persistence of a three-species food chain with non-linear functional responses (McCann and Hastings 1997; McCann and others 1998). First, an unstable equilibrium tends to become locally stable with the addition of omnivory. Additionally, omnivory tends to keep the minima attained by non-equilibrium attractors further away from zero, making the system more persistent (McCann and Hastings 1997). This stabilizing effect of omnivory is confirmed by our model results. However, whether omnivory is stabilizing or destabilizing depends on the model assumptions and also on the stability conditions of the parent system from which it derives (Vandermeer 2006).

Our results also suggest another stabilizing effect, that omnivory can prevent catastrophic regime shifts in the dynamics of predator-prey interactions. We have shown that even omnivorous fish with very strong preferences for zooplankton $(p$ very close to 1) can prevent hysteresis in the response of plankton to predation pressure by fish over a large parameter range. This is because prey 
switching prevents zooplankton from becoming overexploited by planktivorous fish. Indeed, prey switching may facilitate coexistence of the intermediate consumer and the omnivore, as the intermediate consumer persists more easily if it is occasionally dropped from the omnivore's diet and can recover from low densities (Holt and Polis 1997; Krivan 2000; Krivan and Diehl 2005). Therefore, we expect a higher persistence of large zooplankton in systems with omnivorous filterfeeding fish compared to systems with zooplanktivorous fish.

Attempts have been made to use filter-feeding fish such as silver carp, bighead carp, and Nile tilapia to reduce phytoplankton biomass and thus improve water quality in some (sub) tropical lakes (for example, Starling 1993; Starling and others 1998; Xie and Liu 2001, Lu and others 2006; Ke and others 2007; Zhang and others 2008). However, reports on their effects on plankton communities and water transparency have been contradictory (Radke and Kahl 2002; Hambright and others 2002; Wang and others 2008; Zhang and others 2008). This biomanipulation strategy has been more effective under eutrophic or hypereutrophic conditions where the phytoplankton community is dominated by colonial or filamentous cyanobacteria and zooplankton are dominated by microzooplankton (Fukushima and others 1999; Radke and Kahl 2002; Xie and Liu 2001; Zhang and others 2008). Our model indeed predicts a unimodal response of equilibrium or mean phytoplankton biomass to increasing filter-feeding fish biomass. In situ enclosures and whole-lake experiments in Chinese lakes further suggest that increased stocking of silver and bighead carps above a critical threshold of approximately $55 \mathrm{~g} / \mathrm{m}^{3}$ (wet weight) can effectively control cyanobacteria blooms (Xie and Liu 2001; Zhang and others 2006, 2008). Interestingly, this threshold is very close to that predicted by our model (assuming fish dry weight is about $1 / 3$ of its wet weight), although our prediction was based on the functional response parameters of another filter-feeding fish species, the Nile tilapia (Turker and others 2003).

The minimal model of planktivory used in our study may help us to understand some effects of planktivores on plankton dynamics. However, minimal models differ from large simulation models in that they do not attempt to include all important aspects. Therefore, they can be used to investigate the logical consequences of isolated mechanisms in a transparent way, but do not obtain a quantitative insight of the relative importance of different mechanisms operating in the field
(Scheffer 1998). Actually, our minimal model ignores several mechanisms that might be important such as fish dynamics, nutrient recycling by consumers, and the size structure of phytoplankton, zooplankton, and fish. We next consider how these additional factors would influence our model results.

The addition of a third differential equation to account for fish dynamics did not change our major conclusion that omnivory by filter-feeding fish stabilizes plankton dynamics (results not shown), which is in agreement with results from more complex models including dynamics of an omnivorous predator (McCann and others 1998; Kuijper and others 2003; Vandermeer 2006; Namba and others 2008). However, when fish biomass is not fixed, neither the homoclinic bifurcation nor the catastrophic regime shifts from stable oscillations to zooplankton extinction would appear. Thus, stabilizing roles of omnivory may be quite different between cases with fixed and dynamic fish biomass.

The lack of consideration of nutrient recycling is a potential weakness of our model. However, assuming that the effects of nutrient recycling and translocation by consumers would be to increase the carrying capacity for phytoplankton, we can predict from Figure 3 that any increase in algal carrying capacity due to nutrient recycling by omnivorous fish would change the position of the bifurcation points to higher fish biomass. This means that a higher fish biomass would be needed for bifurcations to occur if we had incorporated nutrient recycling into the model, which does not qualitatively change our model predictions but could result in unrealistically high fish biomass for successful control of phytoplankton biomass through fish grazing.

Even though our model predicts low phytoplankton biomass at very high biomass of filterfeeding planktivores, there is currently a lack of empirical evidence supporting this prediction. To the contrary, a positive interaction (synergism) between filter-feeding fish and trophic state has been previously demonstrated (Drenner and others 1996, but see Menezes and others 2010). Our predictions arise because fish nutrient recycling and heterogeneity within phytoplankton have been omitted. At high levels of filter-feeding fish biomass, fish grazing on net-phytoplankton may not reduce total phytoplankton biomass for at least two reasons: (1) nano-phytoplankton will be favored over net-phytoplankton, while the overall biomass carrying capacity of phytoplankton may remain unaltered; (2) high fish biomass will also 
induce high excretion rates that may compensate for the loss from grazing.

It is important here to make a distinction between pelagic (for example, silver carp, Nile tilapia) and bottom-oriented filter-feeding planktivores (for example, common carp, Congo tilapia, gizzard shad) because they have distinct impacts on plankton communities. Bottom-oriented filterfeeding planktivores enhance phytoplankton via nutrient enrichment resulting from bioturbation during their foraging activities near bottom sediments. This mechanism does not exist in most pelagic filter-feeding planktivores.

To summarize, the major controversy regarding the stocking of filter-feeding fish to control phytoplankton blooms is that it may increase the nutrient cycling and improve the growth conditions for small algae by removing both their zooplankton grazers and their major competitors (that is, large algae and cyanobacteria). None of these mechanisms are incorporated in our simple minimal model. Nevertheless, our model closely represents management conditions where filterfeeding fish are stocked within cages to prevent access to the sediment with the aim to control cyanobacteria blooms in eutrophic or hypereutrophic lakes (Starling and Lazzaro 2005). This ecological cage aquaculture can potentially be a successful strategy to improve the water quality of highly productive lakes where reduction of external nutrient loading is not possible or economically feasible. It has already been experimentally tested (Starling and Lazzaro 2005) and a full-scale program will be implemented in Lake Paranoa, Brazil, by 2010.

In conclusion, our model results suggest that omnivorous filter-feeding fish have different effects on plankton dynamics compared to zooplanktivorous fish. Overall, omnivory by planktivores should stabilize plankton dynamics and prevent catastrophic regime shifts. This result has implications for the generality of shallow lakes theory because omnivory by planktivores is widespread among (sub) tropical lakes (Jeppesen and others 2005, 2007). This result may also have consequences for plankton dynamics in many other freshwater, estuarine, and marine ecosystems. Filter-feeding is a common foraging behavior of many planktivorous fish and many benthic and pelagic invertebrates in both marine and freshwater ecosystems. Therefore, our theoretical findings on the impacts of filter-feeding fish on plankton dynamics can potentially be extended to other taxonomic groups of filter-feeding planktivores.

\section{ACKNOWLEDGMENTS}

We thank Patricia Soranno and two anonymous reviewers for their comments and suggestions to improve the manuscript. JLA also thanks CNPq, WIMEK and CAPES for financial support that made possible his visits to Wageningen University.

\section{OPEN ACCESS}

This article is distributed under the terms of the Creative Commons Attribution Noncommercial License which permits any noncommercial use, distribution, and reproduction in any medium, provided the original author(s) and source are credited.

\section{REFERENCES}

Attayde JL, Menezes RF. 2008. Effects of fish biomass and planktivore type on plankton dynamics. J Plankton Res 30:885-92.

Brooks JL, Dodson SI. 1965. Predation, body size and composition of plankton. Science 150:28-35.

Canonico GC, Arthington A, McCrary JK, Thieme ML. 2005. The effects of introduced tilapias on native biodiversity. Aquat Conserve Mar Freshw Ecosyst 15:463-83.

Diehl S. 1993. Relative consumer sizes and the strengths of direct and indirect interactions in omnivorous feeding relationships. Oikos 68:151-7.

Diehl S. 2003. The evolution and maintenance of omnivory: dynamic constraints and the role of food quality. Ecology 84(10):2557-67.

Diehl S, Feissel M. 2000. Effects of enrichment on three-level food chains with omnivory. Am Nat 155(2):200-18.

Drenner RW, Smith JD, Threlkeld ST. 1996. Lake trophic state and the limnological effects of omnivorous fish. Hydrobiologia 319:213-23.

Figueredo CC, Giani A. 2005. Ecological interactions between Nile tilapia (Oreochromis niloticus. L.) and the phytoplanktonic community of the Furnas Reservoir (Brazil). Freshw Biol 50:1391-403.

Folke C, Carpenter S, Walker B, Scheffer M, Elmqvist T, Gunderson L, Holling CS. 2004. Regime shifts, resilience and biodiversity in ecosystem management. Ann Rev Ecol Syst 35:557-81.

Fukushima M, Takamura N, Sun L, Nakagawa M, Matsushige K, Xie P. 1999. Changes in the plankton community following introduction of filter-feeding planktivorous fish. Freshw Biol 42:719-35.

Hambright KD, Blumenshine SC, Shapiro J. 2002. Can filterfeeding fishes improve water quality in lakes? Freshw Biol 47:1173-82.

Hansson LA, Annadoter H, Bergman E, Hamrin SF, Jeppesen E, Kairesalo T, Luokkanen E, Nilsson PA, Sondergaard M, Strand J. 1998. Biomanipulation as an application of food-chain theory: constraints, synthesis, and recommendations for temperate lakes. Ecosystems 1:558-74.

Holling CS. 1973. Resilience and stability of ecological systems. Ann Rev Ecol Syst 4:1-23. 
Holt RD, Polis GA. 1997. A theoretical framework for intraguild predation. Am Nat 149:745-64.

Jeppesen E, Jensen JP, Sondergaard M, Lauridsen T, Pedersen LJ, Jensen L. 1997. Top-down control in freshwater lakes: the role of nutrient state, submerged macrophytes and depth. Hydrobiologia 342(343):151-64.

Jeppesen E, Sondergaard M, Mazzeo N, Meerhoff M, Branco CWC, Huszar V, Scasso F. 2005. Lake restoration and biomanipulation in temperate lakes: relevance for subtropical and tropical lakes. In: Reddy MV, Ed. Tropical eutrophic lakes: their restoration and management. Enfield: Science Publishers. p 331-59.

Jeppesen E, Meerhoff M, Jacobsen BA, Hansen RS, Sondergaard M, Jensen JP, Lauridsen TL, Mazzeo N, Branco CWC. 2007. Restoration of shallow lakes by nutrient control and biomanipulation: the successful strategy varies with lake size and climate. Hydrobiologia 581:269-85.

Ke Z, Xie P, Guo L, Liu Y, Yang H. 2007. In situ study on the control of toxic microcystis blooms using phytoplanktivorous fish in the subtropical Lake Taihu of China: a large fish pen experiment. Aquaculture 265:127-38.

Krivan V. 2000. Optimal intraguild foraging and population stability. Theor Popul Biol 58:79-94.

Krivan V, Diehl S. 2005. Adaptive omnivory and species coexistence in tri-trophic food webs. Theor Popul Biol 67:85-99.

Kuijper LD, Kooi BW, Zonneveld C, Kooiman SALM. 2003. Omnivory and food web dynamics. Ecol Model 163:19-32.

Lazzaro X. 1987. A review of planktivorous fishes: their evolution, feeding, behaviours, selectivities, and impacts. Hydrobiologia 146:97-167.

Lazzaro X. 1997. Do the trophic cascade hypothesis and classical biomanipulation approaches apply to tropical lakes and reservoirs? Verh Int Verein Limnol 26:719-30.

Lazzaro X, Drenner RW, Stein RA, Smith JD. 1992. Planktivores and plankton dynamics: effects of fish biomass and planktivore type. Can J Fish Aquat Sci 49:1466-73.

Lazzaro X, Bouvy M, Ribeiro-Filho RA, Oliveira VS, Sales LT, Vasconcelos ARM, Mata MR. 2003. Do fish regulate phytoplankton in shallow eutrophic Northeast Brazilian reservoirs? Freshw Biol 48:649-68.

Lu K, Jin C, Dong S, Gu B, Bowen S. 2006. Feeding and control of blue-green algal blooms by tilapia (Oreochromis niloticus). Hydrobiologia 568:111-20.

May RM. 1977. Thresholds and breakpoints in ecosystems with multiplicity of stable states. Nature 269:471-7.

McCann K, Hastings A. 1997. Re-evaluating the omnivorystability relationship in food webs. Proc R Soc Lond B 264: 1249-54.

McCann K, Hastings A, Huxel GR. 1998. Weak trophic interactions and the balance of nature. Nature 395:794-8.

Menezes RF, Attayde JL, Vasconcelos FR. 2010. Effects of omnivorous filter-feeding fish and nutrient enrichment on the plankton community and water transparency of a tropical reservoir. Freshw Biol 55:767-79.

Mylius SD, Klumpers K, de Roos AM, Persson L. 2001. Impact of intraguild predation and stage structure on simple communities along a productivity gradient. Am Nat 158(3):259-76.

Namba T, Tanabe K, Maeda N. 2008. Omnivory and stability of food webs. Ecol Complex 5:73-85.

Noy-Meir I. 1975. Stability of grazing systems: an application of predator prey graphs. J Ecol 63:459-82.
Okun N, Brasil J, Attayde JL, Costa IAS. 2008. Omnivory does not prevent trophic cascades in pelagic food webs. Freshw Biol 53:129-38.

Perrow MR, Meijer ML, Dawidowicz P, Coops H. 1997. Biomanipulation in shallow lakes: state of the art. Hydrobiologia 342(343):355-65.

Polis GA, Myers CA, Holt RD. 1989. The ecology and evolution of intraguild predation: potential competitors that eat each other. Ann Rev Ecol Syst 20:297-330.

Post DM, Conners ME, Goldberg DS. 2000. Prey preference by a top-predator and the stability of linked food chains. Ecology 81:8-14.

Radke RJ, Kahl U. 2002. Effects of a filter-feeding fish [silver carp, Hypophthalmichthys molitrix (Val.)] on phyto- and zooplankton in a mesotrophic reservoir: results from an enclosure experiment. Freshw Biol 47:2337-44.

Rondel C, Arfi R, Corbin D, Bihan FL, Ndour EH, Lazzaro X. 2008. A cyanobacterial bloom prevents fish trophic cascades. Freshw Biol 53:637-51.

Scheffer M. 1991. Fish and nutrients interplay determines algal biomass: a minimal model. Oikos 62:271-82.

Scheffer M. 1998. Ecology of shallow lakes. London: Chapman 8 Hall.

Scheffer M, De Boer RJ. 1995. Implications of spatial heterogeneity for the paradox of enrichment. Ecology 76:2270-7.

Scheffer M, Rinaldi S. 2000. Minimal models of top-down control of phytoplankton. Freshw Biol 45:265-83.

Scheffer M, Hosper SH, Meijer ML, Moss B. 1993. Alternative equilibria in shallow lakes. Trends Ecol Evol 8:275-9.

Scheffer M, Rinaldi S, Kuznetsov YA. 2000. Effects of fish on plankton dynamics: a theoretical analysis. Can J Fish Aquat Sci 57:1208-19.

Scheffer M, Carpenter S, Foley JA, Folke C, Walker B. 2001. Catastrophic shifts in ecosystems. Nature 413:591-6.

Starling FLRM. 1993. Control of eutrophication by silver carp (Hypophthalmichthys molitrix) in the tropical Paranoá Reservoir (Brasilia, Brazil): a mesocosm experiment. Hydrobiologia 257:143-52.

Starling FLRM, Lazzaro X. 2005. Using biomanipulation to control eutrophication in a shallow tropical urban reservoir (Lago Paranoá, Brazil). In: Reddy MV, Ed. Tropical eutrophic lakes: their restoration and management. Enfield: Science Publishers. p 361-87.

Starling F, Beveridge M, Lazzaro X, Baird D. 1998. Silver carp biomass effects on the plankton community in Paranoa reservoir (Brazil) and an assessment of its potential for improving water quality in lacustrine environments. Int Rev Hydrobiol 83:499-507.

Stein RA, DeVries DR, Dettmers JM. 1995. Food-web regulation by a planktivore: exploring the generality of the trophic cascade hypothesis. Can J Fish Aquat Sci 52:2518-26.

Turker H, Eversole AG, Brune DE. 2003. Filtration of green algae and cyanobacteria by Nile tilapia, Oreochromis niloticus, in the Partitioned Aquaculture System. Aquaculture 215: 93-101.

van Leeuwen E, Lacerot G, van Nes E, Hemerik L, Scheffer M. 2007. Reduced top-down control of phytoplankton in warmer climates can be explained by continuous fish reproduction. Ecol Model 206:205-12.

Vandermeer J. 2006. Omnivory and the stability of food webs. J Theor Biol 238:497-504. 
Vanni MJ. 2002. Nutrient cycling by animals in freshwater ecosystems. Annu Rev Ecol Syst 33:341-70.

Wang HJ, Liang XM, Jiang PH, Wang J, Wu SK, Wang HZ. 2008. TN:TP ratio and planktivorous fish do not affect nutrientchlorophyll relationships in shallow lakes. Freshw Biol 53:935-44.

Xie P, Liu J. 2001. Practical success of biomanipulation using filter-feeding fish to control cyanobacteria blooms: a synthesis of decades of research and application in a subtropical hypereutrophic lake. Scientific World Journal 1:337-56.

Zambrano L, Scheffer M, Martinez-Ramos M. 2001. Catastrophic response of lakes to benthivorous fish introduction. Oikos 94:344-50.
Zambrano L, Martinez-Meyer E, Menezes N, Peterson AT. 2006. Invasive potential of common carp (Cyprinus carpio) and Nile tilapia (Oreochromis niloticus) in American freshwater systems. Can J Fish Aquat Sci 63:1903-10.

Zhang X, Xie P, Hao L, Guo N, Gong Y, Hu X, Chen J, Liang G. 2006. Effects of the phytoplanktivorous silver carp (Hypophthalmichthys molitrixon) on plankton and the hepatotoxic microcystins in an enclosure experiment in a eutrophic lake, Lake Shichahal in Beijing. Aquaculture 257:173-86.

Zhang X, Xie P, Huang X. 2008. A review of non-traditional biomanipulation. Scientific World Journal 8:1184-96. 